\title{
A Perspective Study on Fame of Pakistani Tele-Serials In India
}

\author{
Shantharaju S, Dr. N.S. Ashok Kumar, \\ Department of Media Studies, Christ University, Hosur Road, Bengaluru-560029 \\ Professor, Department of Mass Communication, central college, Bangalore University, Bengaluru-560
}

009

\begin{abstract}
Zindagi TV also know as, Zee Zindagi is an Indian Hindi-Urdu general entertainment channel, owned by Zee Entertainment Enterprises (ZEEL) was started in June 2014. This channel broadcasts Pakistani Soaps to Indian sub-continent. Since its beginning, these shows were attracted by viewers and with increasing TRP, more shows started getting recognized. This research paper tries to analyze the reasons for the rising popularity of these Pakistani soap operas among Indian viewers inspited of different political climate around both the countries. To focus on micro manifestions of visual media, the paper has focused on one show Zindagi Gulzar Hai.
\end{abstract}

Keywords: Serials, Pakistan, Zindagi Channel

\section{INTRODUCTION}

Indian TV serials have been popular since the beginning of shows like Doordarhan's Hum log in 1984 to the recent ones like Yeh Hai Mohabbatein in 2015. They have a reputation of running for a long duration, many of which go on for years together characterized by elaborate melodrama, dialogues, costume and makeup etc. The storyline considered are either family sentiments or humor and sometimes a combination of both. The progression of the character depends on the accused characterizations. These characters are made in such a way that, they identify with viewers' psyche, deepening the audience beliefs. To emphasize the emotions of the characters, mostly innumerable close-ups along with heightened background music are used as a common visual technique.

The format has taken many shapes with the changing technology. Soap operas have become more glamorous, filmy, young, and of course, high-budget in terms of productions. When we look further into this context, we find the foreign soap operas are also popular in Indian households. Zindagi Gulzar Hai, Aunn Zara, Darmiyan etc. are few to name among the soap operas that were produced in Pakistan. Pakistani serials, which started being aired in Indian channel since 2013. Pakistani dramas are produced mostly in telenovela and miniseries formats in Pakistan, which are usually very distinct from the western serials and dramas that are watched in India. HUM TV in Pakistan features all the miniseries. These TV dramas made an entry into India in 2014 when ZEE Entertainment Enterprises started a new channel called Zindagi. Though Pakistani serials have been banned in India, this channel has the rights to telecast syndicated Pakistani TV dramas.

On June 23, 2014, Zindagi aired the drama called 'Aunn Zara' which was the first time a series was broadcast within 20 days of its start in India. Aunn Zara, instantly caught the attention of Indian audiences and that is when people started looking out for more Pakistani shows. These dramas and series have an identity of their own and have a different style of storytelling which has caught a lot of attention worldwide, especially in India.

Upon taking a closer look on the viewing habits and to understand the receptive pattern of Pakistani serials among Indian audience, the researcher would be finding out more about the popularity of these soap operas, the reasons for it and will be taking some expert opinions on the same.

\section{REVIEW OF LITERATURE}

The topic chosen by the researchers is mainly centered on daily soap operas. So the content chosen for the review of literature was based on terms like 'daily soaps', 'television', 'Pakistani media', 'Pakistani serials' etc. Most of the literature chosen was journals and research papers since they were found to be more specific to the topics.The first paper that the researchers read was National texts and gendered lives: ethnography of television viewers in a north Indian city by Purnima Mankekar, Stanford University'. In this paper, the researcher mostly interprets about how television serials were perceived by viewers belonging to Northern India. She speaks about what the factors are and how these factors influenced the TV viewing pattern of the audience there.

The content of the serial, the way it is telecasted and the topics that it addresses, all of these questions were raised and studied. The author also spoke to a couple for a prolonged period, watched some shows with them 
and tried to make inferences pertaining to what they watched and how they perceived it. The shows were also judged on matters of how they approached their central theme and went about showing it to the audience.

The second paper reviewed by the researchers was Contemporary Woman in Television Fiction Deconstructing Role of 'Commerce' and 'Tradition'.

The paper brings to light the fact that television serials show a variety of programme to the audience. This plethora of genres is vital for a socio-cultural experience. Women play a major role when we discuss about television serials and this research paper deals with this very theme. It talks about women playing dual roles in the field of media. They are the protagonists of most shows and they are also the target audience. TV serials are thus catering to women in majority perspective.

This paper then talks about how women and feminism in particular has a dual impact on the entire field of serials and daily soaps. They are strong stakeholders since the trade and economic section relating to the TV industry, and thus what they watch plays an important role. What roles they play also plays an important in completing this chain of event.

In the paper, The trauma of TV's troubled Soap families, M L Ramsdell talks about the kind of topics and themes that the daily soaps

The questions that this research paper raised were what kind of role models and family behavior patterns are they offering not only to adult viewers, but to those incidental viewers, the preschool children? How accurate are the conceptions of the social order being acquired by preschool viewers of daytime dramas? These questions helped the researcher to look the research topic through the perspective of questions and then trying to find out the answers to these questions.

The next paper which was Pakistan: Too Much Politics by S Akbar Zaidi gave a better view about the topic of current discussion. Since the research is all about Pakistani serials, the above mentioned paper was important to give the researchers a view on the state of media there. Since there is a lot of politics in Pakistan, the mainstream media caters to all the news that is confined to politics. On the other hand, it was a topic of interest for the researcher to see if this influence is prevalent in the TV media as well.

The final paper that was reviewed was 'Other Worlds: Society Seen Through Soap Opera' Dorothy Anger. Peterborough, Ontario'

This was a paper that tried to make a connection between the two different world; one being real and the other being the fictional TV serial world. The writers were successful in coming up with typical stereotypes and how over the years these stereotypes have becomes common that we have started considering it to be real.

Researching on soap operas gives us an insight into the working of our society. The kind of roles, issues, environment etc that are shown in operas, reflect how our society is. If it doesn't reflect, it at least gives us a forum to compare."

\section{RESEARCH OBJECTIVES}

Pakistani soap operas are creating a niche audience among Indians and thus their popularity rates have now become something of interest to people. The research objectives of this particular research are-

- To analyze Pakistani soap opera, Zindagi Gulzar Hai, aired on the channel Zindagi

- To study the various elements like storyline, production setting, costume, make-up and acting present in these TV operas

- To find out the shift in their popularity and to analyze the reasons for the same

Hypothesis

Pakistani dramas started playing on the Indian channel 'Zindagi' from 2014. These Pakistani shows over the span of two years have become extremely popular among Indian audiences. The reason behind their rising popularity is their crisp storyline, professional actors and most importantly, their short span. These shows are also very realistic in nature.

\section{METHODOLOGY}

The research has adopted a qualitative research methodology in order to conduct this research. Qualitative research methodology is the use of non-quantifiable methods to conduct evaluation of a topic. It pays more attention into the descriptions rather than the numbers or figures. Content analysis is an important part of qualitative research which provides the researcher ways to analyze the text for the research. In order to evaluate the contemporary trends in TV viewing habits, the researcher analyzed five different Pakistani soap operas and special reference was given to the show Zindagi Gulzar Hai.

The researchers analyzed Zindagi Gulzar Hai and also closely observed each episode to understand the unique features in the story. Further, an expert interview was also conducted in order to get a comparison between Indian and Pakistani soap operas and to be able to understand the topic more clearly. 
A code in qualitative inquiry is most often a word or short phrase that symbolically assigns a summative portion of language-based or visual data. This helps to differentiate between the various levels that exist in the elements that you are analyzing.

\title{
Coding applied-
}

In this research paper, coding was applied for the setting and costume and make-up as categorized below.

\author{
Setting \\ 1- Rich \\ 2- Middle-class \\ 3- Poor \\ 4- Minimalistic \\ 5- Colorful \\ Costume \\ 1- Bright and Colorful \\ 2- Western style \\ 3- Traditional Pakistani \\ 4- Pastel color costumes \\ 5- Rich and expensive \\ Make-up \\ 1- Heavy and rich \\ 2- Simple \\ 3- Bold colors (lipsticks, eye-shadows) \\ 4- No make-up
}

\section{Analysis- Zindagi Gulzar Hai}

In order to understand and analyze the topic, the researcher watched five Pakistani serials and Zindagi Gulzar hai was chosen as a special reference.

\section{Storyline}

Zindagi Gulzar Hai revolves around the lives of Kashaf and Zaroon, played by Sanam Saeed and Fawad Khan. Kashaf hails from a lower middle class family, who is also the eldest of three sisters. Kashaf's father had abandoned her mother as she didn't bear a son for him. This has a strong impact on Kashaf and her personality as she is a very independent woman who lives by her terms. Zaroon hails from a rich family and has everything that he can wish for. He is a flirt and has had many girlfriends. Zaroon and Kashaf meet while they are pursuing their education in a prestigious university. The story then revolves around how Zaroon falls in love with Kashaf, who initially after ignoring him, agrees to marry him. In their happy life, some misunderstandings rise and how the couple tackles it becomes the story.

The story is a typical one where we see a rich and flirtatious boy who falls for the simple yet strong girl who comes from a poor family background. Yet, there is a difference in the way the two characters are portrayed. Kashaf, although from a poor family, is a strong character who believes women can do anything they want to Sanam Saeed has portrayed the character of Kashaf with utmost passion. The serial doesn't show Kashaf crying over her poverty or the fact that her father abandoned them. Instead, she works on her studies, makes a career for herself and likes to depend on nobody. Similarly, even though Zaroon hails from a rich family, he is not the typical spoilt brat. He understands his responsibilities, supports his family and tries to balance his work and personal life.

The story also breaks the typical stereotype of a poor girl who needs a man to live her life. When Kashaf gets pregnant and realizes that she is carrying twin girls, she gets worried that Zaroon would leave her. But in reality, Zaroon is happy to know about the girls and the show ends with a positive scene where Kashaf and Zaroon share the joys of having daughters in their life. Thus, the story tries to send a social message as well. There are no dramatic twists like rebirths, murders or divorces but it's a practical story, one that any couple could come across.

\section{Production and Setting}

Unlike what we see in Indian serials where even a economically lower family stays in a huge bungalow or apartment, Kashaf's home is a small house that perfectly displays her status. Similarly, even though Zaroon is rich, he isn't seen flaunting his millions with huge cars or gadgets. It is kept close to reality. Most episodes show both the rich and the middle-class backgrounds to establish the difference in the upbringing and status of both 


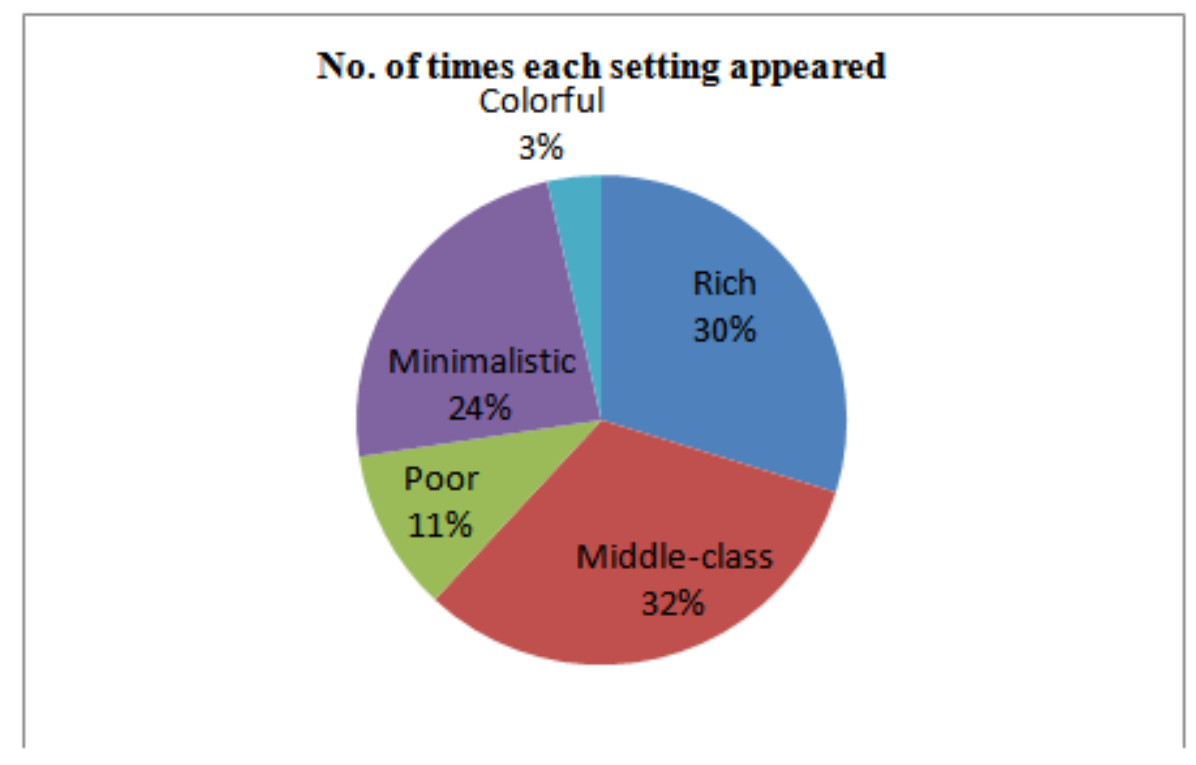

Figure1 : Type of settings in Zindagi Gulzar Hai

From the figure one, most of the setting is dominated by Middle class and Rich who shares more than $60 \%$ together, followed by $24 \%$ of minimalistic, $11 \%$ by poor setting depiction. Zaroon and Kashaf

\section{Costume and Make-up}

You will not find any elaborate costumes to show the difference between a poor and a rich family. Kashaf's family wears modest clothing while Zaroon's family also is not seen in diamonds or gaudy clothing. Even during the wedding scenes, there is no heavy expenditure depicted. Similarly, the make-up also is minimal and most of the actors look natural. Even the characters that have some negative shades are not seen in elaborate makeup. The makeup and costume helps the audience to connect better with the actors.

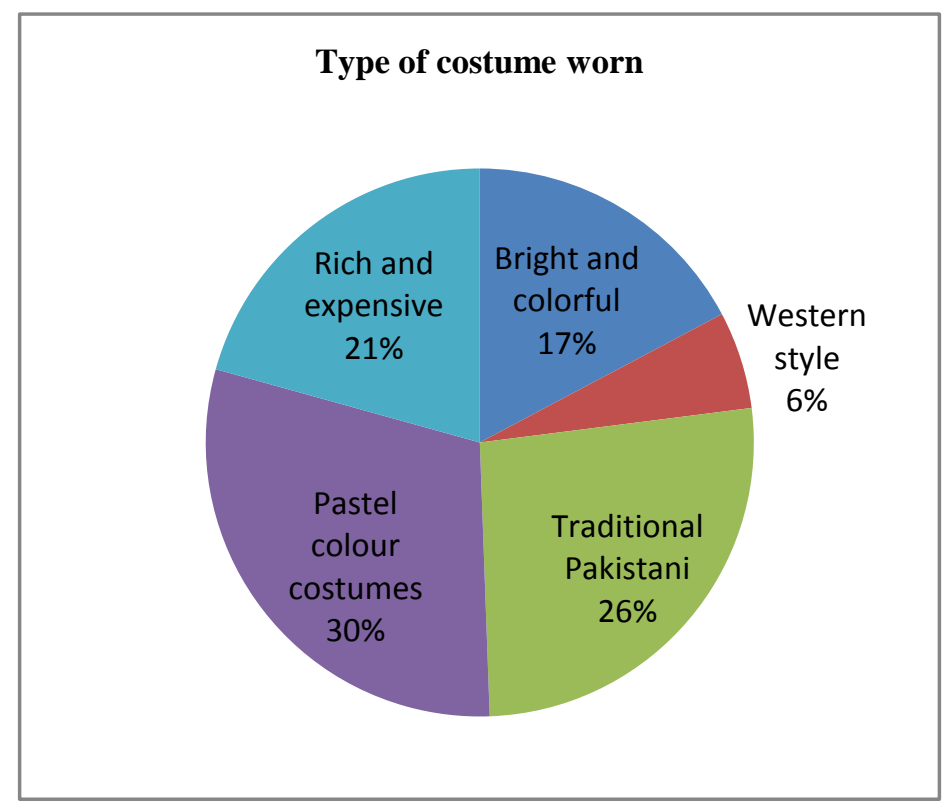

Figure 2: Type of Costumes in ZGH 
From the above graph, it is know that about 30 percent of costume is of pastel colors, followed by $26 \%$ of typical Pakistani, $21 \%$ of Rich and expensive and 17 percent of bright and color. Interestingly $6 \%$ of Western Style.

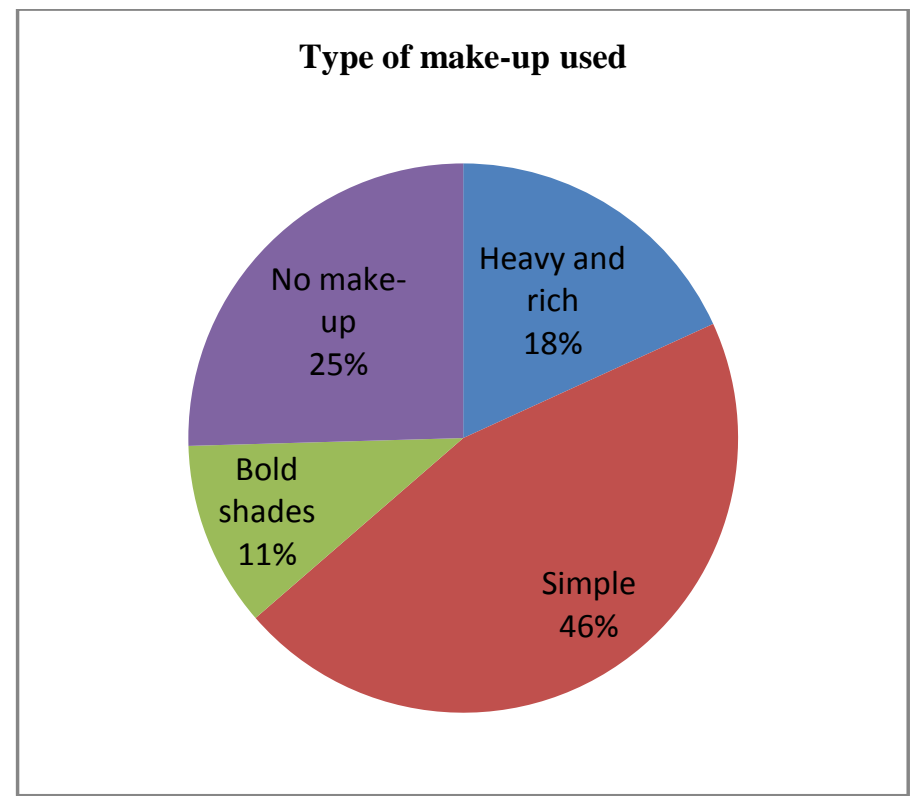

Figure 3 Type of make-up used in Zindagi Gulzar Hai

From the above graph, it is understood that $46 \%$ of make-up was pretty simple, unless in Indian scenario of over usage of color and Make-up, irrespective of its necessity.

\section{Camera Movements}

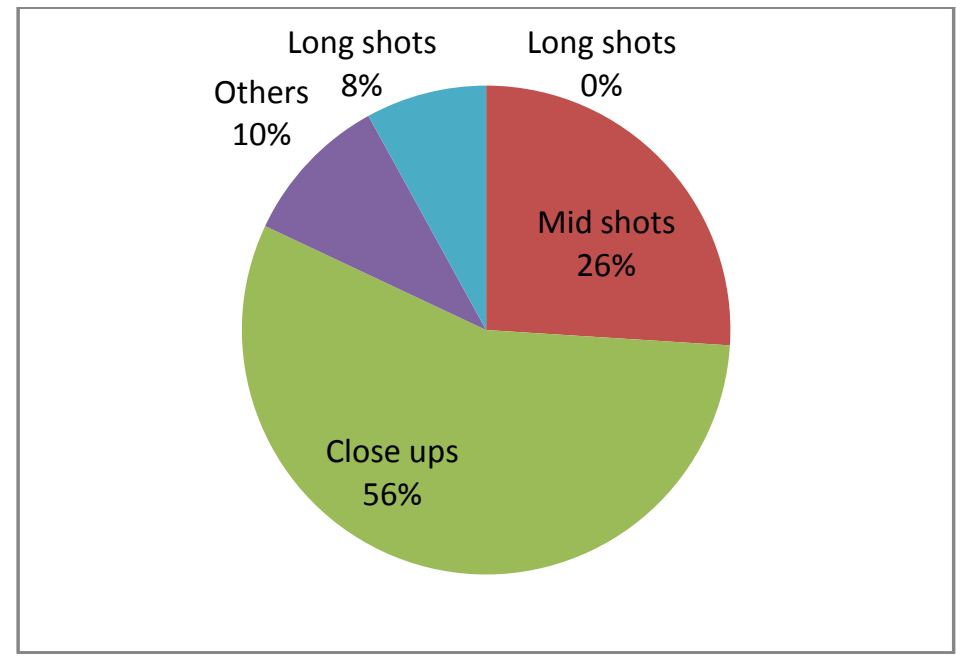

Figure 4: Camera movements

TV serials are thought to be an amalgamation of drastic camera movements that pan around a character for at least three times to show the intensity of a scene. However, you will not find any such camera movement in Pakistani dramas From the above figure of couple shows shots, $56 \%$ of shots were close ups, followed by $26 \%$ of long shots, $8 \%$ by long shots and 10 percent of Extreme long, Extreme close up and other shots. It has to be noted that dolly shots in Indore and follow shots in outdoors were also commonly used in all the episodes. 
Acting

One of the main reasons why Pakistani serials are becoming popular is because of the actors. All the actors, from the leading ones to supporting actors, portray simple yet, realistic acting. There are no incessantly crying daughter-in-laws or the loud mother-in-laws. The acting is so real that the audience can feel their emotions connect easily with them.

Kashaf's mother-in-law is not the typical negative role that conspires against her daughter-in-law. Even though she doesn't approve of Kashaf and Zaroon's marriage, she doesn't try to break their marriage. In fact, she agrees to Zaroon's wishes and never once tries to behave with Kashaf in an undignified manner. The saga of typical in-laws war is not overtly portrayed nor exists in the soaps.

\section{Episode Analysis}

Under episode analysis, the researcher aims to bring to notice certain offbeat characteristics found in Zindagi Gulzar Hai, which highlight their uniqueness. Every episode begins with a minute-long recap which helps the audience to maintain continuity in their viewing pattern. This recap also makes it easier for new viewers to start watching the show from any episode. The establishment shots of each episode usually involve showing the locale. For example, some episodes begin with the huge bungalow where Zaroon lives and some other times it would be the University where Zaroon and Kashaf were studying. All the episodes end with a scene that does not have many loose ends unlike what we see usually. For example, episode 20 ends with Kashaf's mother making her realize about how Zaroon, although being from a rich background, has a good understanding of human beings and that he does not confine his relationships to his social status. Similarly, in the episode where Kashaf and Zaroon get married, the episode ends with snapshots of their wedding that depict happiness, family bonding, new relationships etc.

The character of Kashaf has many layers to it. In episode 19, when Zaroon takes her out for dinner, the audience is given a peek into the mind of Kashaf who portrays a modern woman of Pakistan. She tells Zaroon that though she is not very liberal, she isn't also the woman who will wait for her husband to boss over her. She also mentions about how husband and wife must walk together and neither should take the dominant power.

\section{CONCLUSION}

Pakistani dramas have short, realistic and crystal clear storyline, in episodes as well as across the entire sequence. The wedding scenes do not go on for days and neither does the story drag along for a long time. The characters and the depth of their relationships are portrayed in a short yet intense manner which the audience can instantly relate to. These TV shows end in a short duration, between 20-50 episodes, which means it will not go on for years like mega serials. Hence the branching out of main theme is avoided. "Unlike what we find in Indian soap operas, there are no characters in the show that come back from the dead or go through numerous plastic surgeries to take revenge on his/her enemies. Thus, they don't stereotype their female leads in any manner" says Pravin Patil, who works as an Assistant Director in the Hindi TV industry

The actors and their acting is a point that cannot be ignored. They act in a realistic manner that isn't artificial at all. "In Pakistani shows, actors depict the characters they play. So if a girl belongs to a poor family, we will find her in simple clothes and not kanjeevaram sarees. The dressing and make-up is very real and thus makes it believable. The actors behave in a manner any normal person would in their daily lives. I would also like to stress upon the fact that Indian soap operas do need to make a shift from their dramatized stories to more realistic ones" adds Pravin Patil.

Also, the endings of the stories are very practical and not fairytale endings. Within a short time, the characters manage to win the hearts of the viewers. These shows are also famous for breaking the stereotypes and sending a social message through the shows.

This does not mean that all Indian soap operas are bad. We have many shows that provide quality content. But there are many ways in which we show negative concepts as well especially when it comes to how we portray women in our shows. There needs to be a definite shift in this case.

\section{SCOPE OF RESEARCH}

Further scope for research pertaining to this topic includes conducting a comparison between selected Indian and Pakistani TV shows. Another scope is a detailed analysis of portrayal of women in Pakistani shows. A research can also be conducted to show how both Indian and Pakistani shows handle similar situations in the lives of their characters. 